\title{
Expert System for Diagnosing Early Symptoms of Stroke Using the Fuzzy Mamdani Method
}

\section{Sistem Pakar Diagnosa Gejala Dini Penyakit Stroke Menggunakan Metode Fuzzy Mamdani}

\author{
Sylfanie Sekar Mayang ${ }^{1}$, Ade Eviyanti ${ }^{2}$ \\ \{sylfaniesekarmayang29@gmail.com¹, adeeviyanti@umsida.ac.id² $\}$ \\ Universitas Muhammadiyah Sidoarjo, Indonesia ${ }^{1,2}$
}

\begin{abstract}
One of the dangerous diseases is stroke because it can disrupt the nervous system system in humans so that sufferers of this disease often experience paralysis in their body parts. Therefore, an application is needed to assist medical personnel when doctors are not available or are not on duty. Expert system applications are needed in early diagnosing the characteristics of the disease suffered by a patient. Expert systems are computer-based systems that use knowledge, facts and reasoning techniques to solve problems. The purpose of this study is to make it easier for researchers to identify problems with stroke based on the symptoms experienced by the patient or a person. The research method used is the fuzzy mamdani method. Data collection techniques are quantitative data techniques. The results that have been achieved from this study are that it can prevent and reduce the risk of stroke that can occur as early as possible in sufferers or the community and reduce the death rate in stroke patients.
\end{abstract}

Keywords - Stroke; Fuzzy Mamdani; Expert System

\begin{abstract}
Abstrak.Salah satu penyakit yang berbahaya adalah penyakit stroke karena dapat mengganggu sistem jaringan syaraf pada manusia sehingga penderita penyakit ini sering mengalami kelumpuhan pada bagian tubuhnya. Oleh karena itu, diperlukan suatu aplikasi untuk membantu para petugas medis disaat dokter tidak ada atau sedang tidak bertugas. Aplikasi sistem pakar sangat dibutuhkan dalam mendiagnosa awal yang ciri-ciri penyakit yangdiderita oleh seorang pasien. Sistem pakar adalah sistem berbais komputer yang menggunakan pengetahuan, fakta dan teknik penalaran yang mampu memecahkan masalah.

Tujuan penelitian ini adalah untuk memudahkan peneliti dalam mengidentifikasi masalah penyakit stroke berdasarkan gejala yang dialami oleh pasien atau seseorang. Metode penelitian yang digunakan adalah metode fuzzy mamdani. Teknik pengumpulan data yaitu teknik data kuantitatif. Hasil yang telah dicapai dari penelitian ini adalah dapat mencegah dan mengurangi resiko penyakit stroke yang dapat terjadi sedini mungkin pada penderita atau masyarakat serta mengurangi tingkat kematian pada pasien penderita stroke.
\end{abstract}

Kata Kunci - Stroke; Fuzzy Mamdani; Sistem Pakar

\section{Pendahuluan}

Penyakit stroke merupakan penyakit yang menyerang bagian otak secara medadak yang dapat mengakibatkan adanya sebuah ganggaun dari fungsi kerja otak yang berakibat terjadi ganggaun aliran darah yang mampu menyebabkan kematian dalam waktu realtif singkat [1]. Apabila tidak segera dilakukan penanganan maka bisa mengakibatkan sebuah kecacatan atau bahkan yang paling fatal kematian.

Penyakit Stroke dapat terjadi karena adanya penyumbatan atau pecahnya pembuluh darah pada bagian otak yang mengakibatkan suplai oksigen berkurang atau terhenti sehingga terdapat bagian otak yang mengalami kerusakan [2]. Oleh sebab itu, maka dapat dilakukan sebuah tindakan yang mampu mendeteksi resiko penyakit stroke dengan cara mendapatkan parameter yang terstruktur dengan mudah. Dalam pencegahan penyakit stroke terdapat faktor permasalahan lain yaitu sulitnya mendapatkan informasi bagaimana menjaga kesehatan dan pemilihan tindakan yang sesuai dan tepat dan cara merawat bagi seseorang yang terkena stroke [3]. Dengan adanya permasalahan tersebut maka, dapat diatasi menggunakan pemanfaatan teknologi, seperti pada saat ini terdapat sebuah kecerdasan buatan yang mampu meniru kecerdasan dari manusia yang disebut Artificial Intelegence (AI) [4].

Oleh sebab itu, untuk mempermudah pasien atau penderita dapat mengetahui diagnosa sejak dini penyakit stroke agar tidak terjadi keterlambatan dan segera mendapat pertolongan serta pengobatan secara tepat[5], maka peneliti akan membuat sebuah "Sistem Pakar Diagnosa Gejala Dini Penyakit Stroke Menggunakan Metode Fuzzy Mamdani” yang bertujuan untuk mempermudah melakukan pendeteksian berdasarkan gejala yang dialami penderita atau pasien dalam pendeteksian resiko penyakit stroke. Selain itu dapat membantu tugas seorang pakar atau dokter dalam melakukan diagnosa serta pendeteksian stroke pada pasien. 


\section{METODE}

\section{Tahap Pengumpulan Data}

Pada penilitian ini, peneliti melakukan penelitian dengan teknik pengumpulan data dengan cara membaca buku dan jurnal yang terkait dengan topik penelitian yang diambil, teknik pengumpulan data yang kedua yaitu dengan mengisi pertanyaan yang sudah dipersiapkan sebelumnya dan melakukan wawancara dengan dokter spesialis atau pakar, kemudian teknik pengumpulan data yang terakhir yaitu melakukan observasi atau mengamati secara langsung.

\section{Subyek dan Obyek Penelitian}

Dalam penelitian ini, peneliti menggunakan subyek yang digunakan adalah pasien di Rumah Sakit Rahman Rahim Sidoarjo dan masyarat umum, sedangkan obyek dari penelitian ini adalah seorang dokter spesialis penyakit dalam atau pakar yang mengerti dan memahami dalam hal penyakit stroke.

\section{Teknik Analisis Masalah}

Masalah penyakit stroke pada seseorang merupakan kategori dari masalah Artificial Inteligent, atau bisa disebut dengan sistem pakar [6]. Untuk memecahkan permasalahan tersebut, maka peneliti membangun sebuah sistem pakar yang menggunakan metode fuzzy mamdani yang dapat membantu dalam penyelesaian masalah tersebut [7].

\section{Kerangka Penelitian}

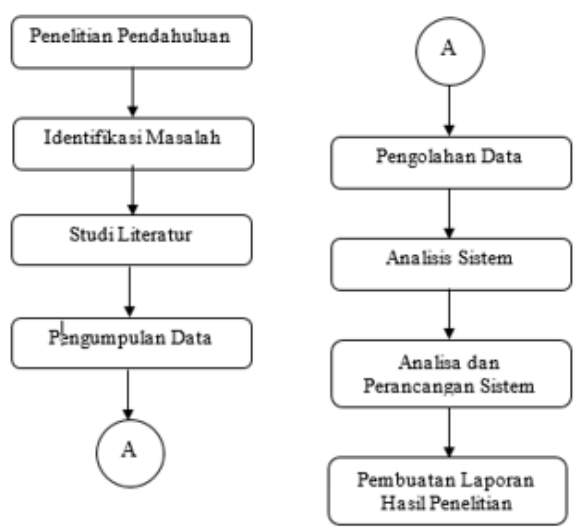

Gambar 1. Tahapan penelitiani

Untuk menghasilkan sebuah penelitiannyang baik dan sesuai dengan sasaran yang ingin dicapai oleh peneliti, maka dibuat sebuah alur penelitian yang berisiilangkah-langkah yang dilakukanndalam penelitian.

Tabel 1. Gejala Stroke

\begin{tabular}{lll}
\hline No.. & Kode Gejala & \multicolumn{1}{c}{ Gejala } \\
\hline 1. & G01 & Separuh batang otak berhenti bekerja \\
2. & G02 & Mati rasa \\
3. & G03 & Salah satu sisi/anggota bagian tubuh terasa lemah \\
4. & G04 & Kelumpuhan pada wajah/paralis \\
5. & G05 & Pusing/bingung \\
6. & G06 & Sulit berbicara/berkomunikasi \\
7. & G07 & Hilang koordinasi/keseimbangan \\
8. & G08 & Gangguan penglihatan/buram \\
9. & G09 & Sakit kepala yang berat \\
10. & G10 & Sulit berjalan \\
11. & G11 & Hilang kesadaran \\
12. & G12 & Terasa baal \\
13. & G13 & Kelumpuhan pada satu sisi tubuh \\
14. & G14 & Nyeri pada bagian wajah/sekitar mata \\
15. & G15 & Leher terasa kaku \\
16. & G16 & Penurunan kesadaran \\
17. & G17 & Sulit bernafas \\
18. & G18 & Kelumpuhan \\
19. & G19 & Kesemutan \\
20. & G20 & Mati rasa dibagian tubuh tertentu \\
21. & G21 & Sulit mengunyah dan menelan \\
& &
\end{tabular}




$\begin{array}{lll}\text { 22. } & \text { G22 } & \text { Vertigo } \\ \text { 23. } & \text { G23 } & \text { Ganggaun pendengaran } \\ \text { 24. } & \text { G24 } & \text { Cegukan tak kunjung henti } \\ \text { 25. } & \text { G25 } & \text { Anggota tubuh terasa lemah secara mendadak } \\ \text { 26. } & \text { G26 } & \text { Mual dan muntah } \\ \text { 27. } & \text { G27 } & \text { Kejang } \\ \text { 28. } & \text { G28 } & \text { Otot terasa lemah pada separuh tubuh } \\ 29 . & \text { G29 } & \text { Buta }\end{array}$

Dari data gejala yang dialami maka akan menghasilkan kesimpulan atau bisa disebut juga dengan hasil identifikasi. . Pada umumnya secara garis besar jenis penyakit stroke terbagi menjadi 2 jenis yaitu stroke perdarahan dan stroke penyumbatan [8]. Jenis penyakit stroke yang akan teridentifikasi pada penelitian ini ada 8 jenis yaitu Stroke Iskemik, Transient Ischemic Attack (TIA), Stroke Perdarahan (Hemorahic Stroke), Stroke Batang Otak, Stroke Perdarahan Intraserebal, Stroke Perdarahan Subarachnoid, Stroke Trombotik, Stroke Embolik.

Tabel 2. Identifikasi Stroke

\begin{tabular}{ccl}
\hline No.. & Kode Penyakitt & Nama Penyakitt \\
\hline 1. & P01 & Stroke Iskemik \\
2. & P02 & Transient Ischemic Attack (TIA) \\
3. & P03 & Stroke Perdarahan (Hemoragic Stroke) \\
4. & P04 & Stroke Batang Otak \\
5. & P05 & Stroke Perdarahan Intraserebal \\
6. & P06 & Stroke Perdarahan Subarachnoid \\
7. & P07 & Stroke Trombotik \\
8. & P08 & Stroke Embolik \\
\hline
\end{tabular}

keputusan pakar pada tabel 4 ini terbentuk dari gejala penyakit stroke.

Tabel 3. Keputusan Pakar

\begin{tabular}{|c|c|c|c|c|c|c|c|c|}
\hline \multirow[b]{2}{*}{$\begin{array}{c}\text { Kode } \\
\text { Gejala }\end{array}$} & \multicolumn{8}{|c|}{ Penyakit } \\
\hline & $\begin{array}{c}\text { Stroke } \\
\text { Iskemik }\end{array}$ & $\begin{array}{l}\text { Transient } \\
\text { Ischemic } \\
\text { Attack } \\
\text { (TIA) }\end{array}$ & $\begin{array}{c}\text { Stroke } \\
\text { perdarahan } \\
\text { (hemorrhagic } \\
\text { stroke) }\end{array}$ & $\begin{array}{c}\text { Stroke } \\
\text { Batang } \\
\text { Otak }\end{array}$ & $\begin{array}{c}\text { Stroke } \\
\text { perdarahan } \\
\text { intraserebral }\end{array}$ & $\begin{array}{c}\text { Stroke } \\
\text { Perdarahan } \\
\text { subarachnoid }\end{array}$ & $\begin{array}{c}\text { Stroke } \\
\text { trombotik }\end{array}$ & $\begin{array}{c}\text { Stroke } \\
\text { Embolik }\end{array}$ \\
\hline G01. & $\mathrm{X}$ & & & & & & & \\
\hline G02. & $X$ & & & & & & $X$ & $X$ \\
\hline G03. & & $X$ & & $X$ & & & & \\
\hline G04. & $X$ & $X$ & & & & & & $X$ \\
\hline G05. & $X$ & $\mathrm{X}$ & & & $X$ & $X$ & $X$ & $X$ \\
\hline G06. & & $X$ & & $X$ & & & $X$ & $X$ \\
\hline G07. & $\mathrm{X}$ & & & & & & $X$ & $X$ \\
\hline G08. & $X$ & $X$ & $X$ & $X$ & $X$ & $X$ & $X$ & $X$ \\
\hline G09. & $\mathrm{X}$ & $X$ & $X$ & & & $X$ & $X$ & $\mathrm{X}$ \\
\hline G10. & $X$ & & & $X$ & & & $X$ & $X$ \\
\hline G11. & $X$ & $X$ & & $X$ & $X$ & $X$ & & \\
\hline G12. & & $X$ & & & & & & \\
\hline G13. & & & & & & & & \\
\hline G14. & & & $X$ & & & & & \\
\hline G15. & & & $X$ & & $X$ & $X$ & & \\
\hline G16. & & & $X$ & $X$ & & & & \\
\hline G17. & & & & $X$ & & & & \\
\hline G18. & & & & $X$ & & & & \\
\hline G19. & & & & $X$ & & & & \\
\hline G20. & & & & $X$ & & & & \\
\hline G21. & & & & $X$ & & & & \\
\hline G22. & & & & $\mathrm{X}$ & & & & \\
\hline G23. & & & & $X$ & & & & \\
\hline G24. & & & & $X$ & & & & \\
\hline G25. & & & & & $X$ & & & \\
\hline G26. & & & & & $\mathrm{X}$ & $X$ & & \\
\hline G27. & & & & & $X$ & $X$ & & \\
\hline G28. & & & & & & & $X$ & \\
\hline G29. & & $X$ & & & & & & \\
\hline
\end{tabular}




\section{HASIL DAN PEMbahaSAN}

\section{Perancangann Sistem}

a. Diagram Konteks

Diagram konteks merupakan alur data yang dapat dilihat berbagai macam data yang mengalir ke dalam sistem

[9]. Adapun perancangannya dapat dilihat pada gambar 2. berikut :

\section{Data penyakit}

Data gejala

Rule

Registrasi Pasien

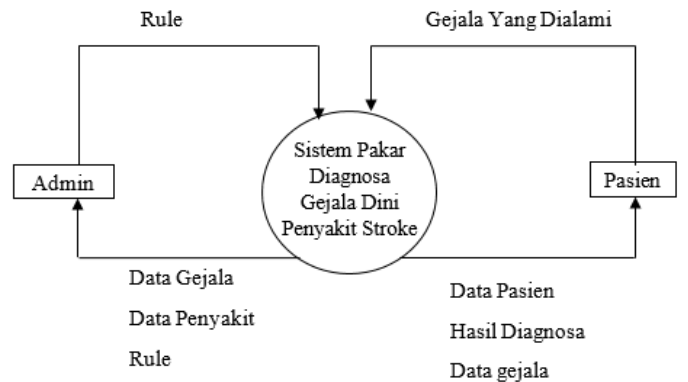

Gambar 2. Diagram Konteksi

b. Data Flow Diagram (DFD)

Data Flow Diagram (DFD) merupakan alat pemodelan dari proses analisis kebutuhan perangkat lunak [10]. Adapun rancangannya adalah seperti pada gambar 3 berikut :

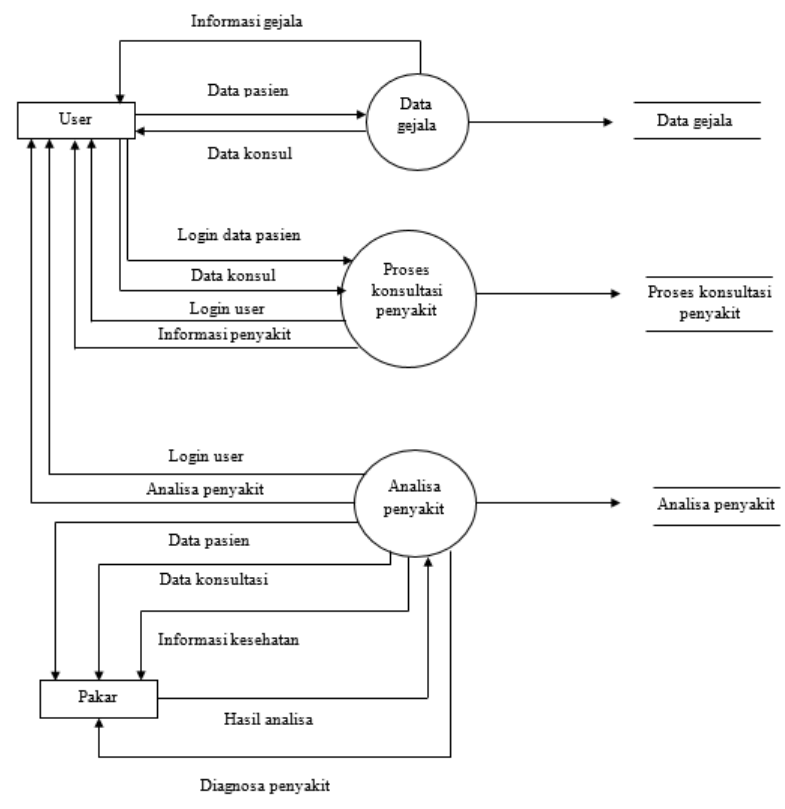

Gambar 3. Data Flow Diagram.(DFD)

D. Entitity RelationshipiDiagrami(ERD) 
ERD digunakan untuk menjelaskan hubungan antar data dalam basis data berdasarkan objek-objek data yang mempunyai hubungan antarirelasi. Berikut adalah rancangan ERD :

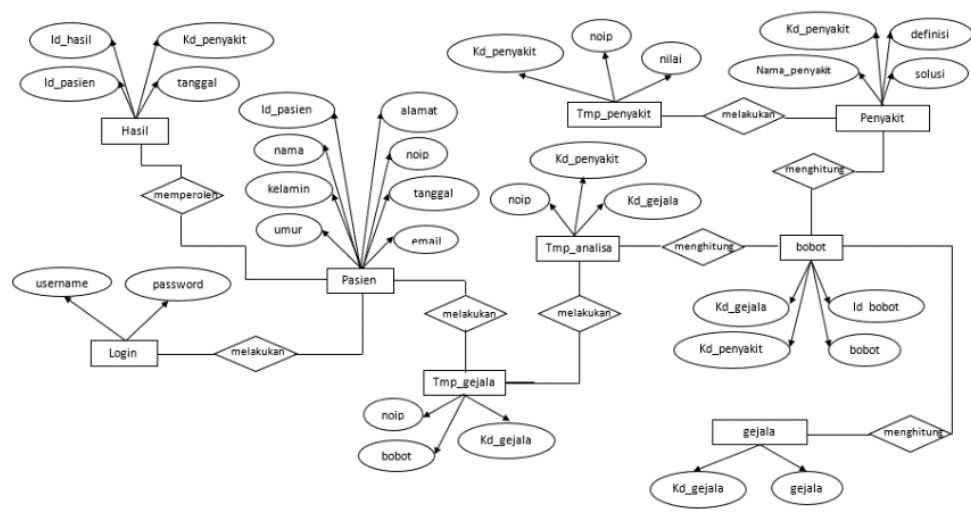

\section{Hasil Penelitian}

Gambar 4. ERD

1. Halaman Proses Diagnosa

Pada halaman ini sebelum pasien melakukandiagnosa menggunakan sistem, pasien harus melakukan proses registrasi pengguna terlebih dahulu.

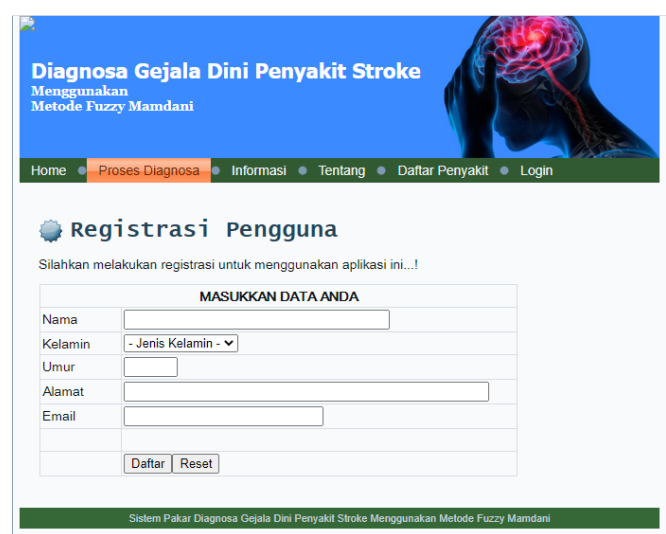

\section{Gambar 5. Halaman Proses Diagnosa}

2. Halaman Foem Konsultasi

Setelah pasien melakukan registrasi, selanjutnya yaitu pasien dapat pemilihan gejala berdasarkan gejalaiyangidialami oleh pasienisesungguhnya.

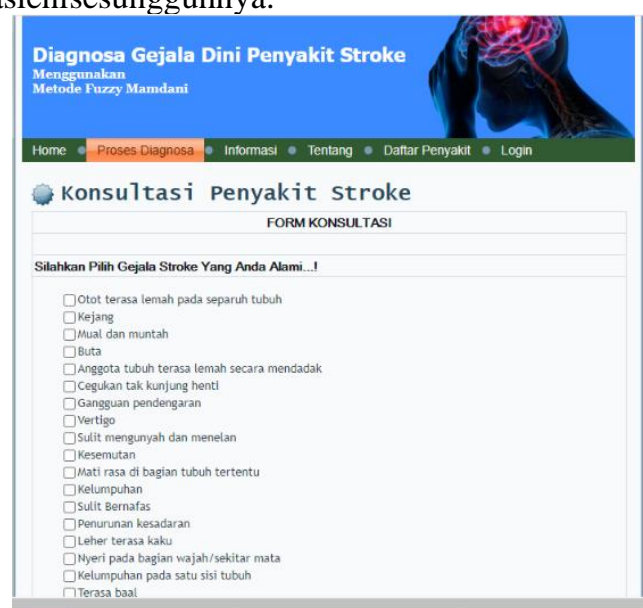

Gambar 6. Halaman Form Konsultasi

3. Halaman Hasil Diagnosa

Pada halaman ini pasien dapat melihat hasil diagnosa berdasarkan gejala-gejala yang telah diinputkan sebelumnya. 


\section{Hasil Uji Coba Sistem}

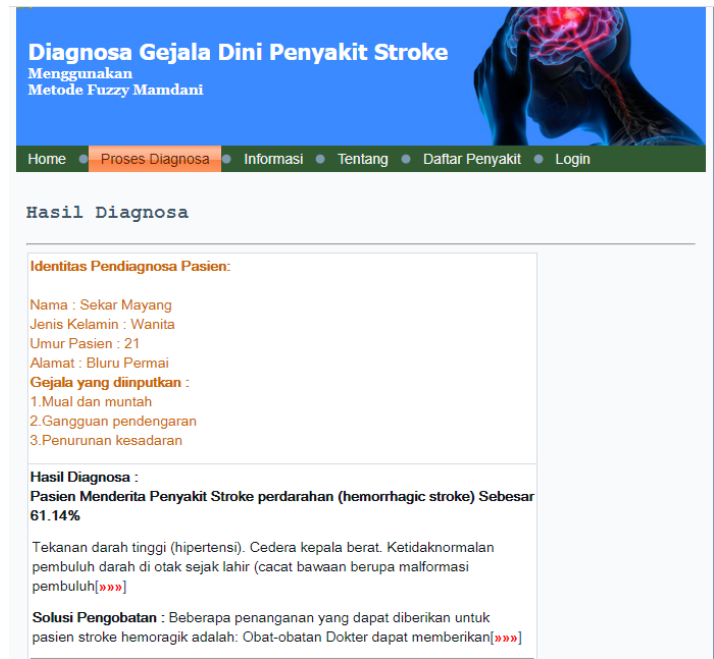

Gambar 7. Halaman Hasil Diagnosa

Pada hasil uji coba ini peneliti melakukan sebuah uji coba sistem terhadap seorang penderita atau pasien penyakit stroke. Dalam hal ini pasien diminta untuk menggunakan aplikasi sistem pakar dan menginputkan gejala berdasarkan gejala yang dialami oleh penderita atau pasien. Berikut merupakan hasil uji coba terhadap seorang penderita atau pasien dapat dilihat pada gambar 8 :

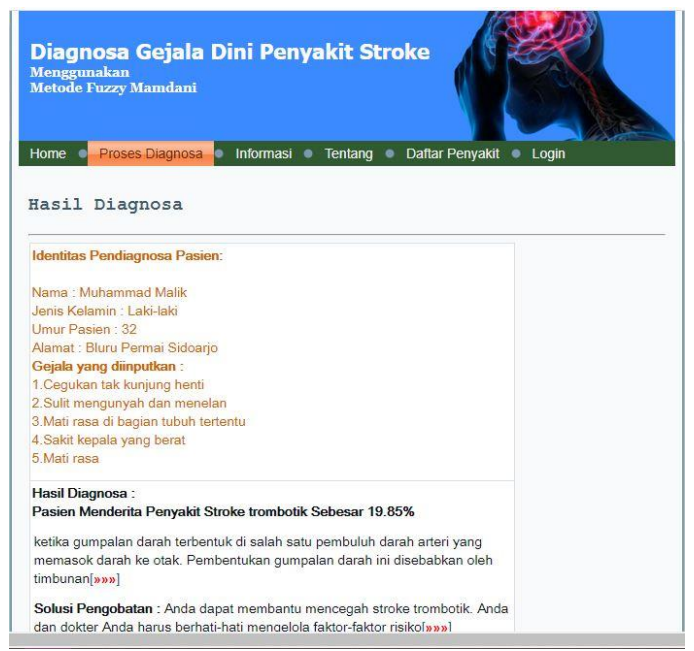

Gambar 8. Hasil Uji Coba Sistem

\section{KESIMPULAN}

Dari hasil penelitian yang telah dilakukan, maka dapat ditarik beberapa kesimpulan diantaranya adalah sebagai berikut : (1) perancangan dan pembuatan sistem pakar dapat mempermudah dalam memberikan informasi bagi pengguna. (2) sistem pakar penyakit stroke dapat memberikan solusi bagi pengguna berdasarkan gejala yang dialami oleh pengguna selayaknya solusi yang diberikan oleh pakar. (3)sistemm pakar ini dapat dijadikan sebagai acuan untk melakukan konsultasi lebih lanjut kepada dokter atau dokter spesialis.

\section{UCAPAN TERIMA KASIH}

Dengan adanya penelitian ini, maka penulis mengucapkan terimakasih banyak kepada semua pihak yang terkait yang sudah membantu dalam melakukan penulisan artikel ilmiah yang berjudul "Sistem Pakar Diagnosa Gejala Dini Penyakit Stroke Menggunakan Metode Fuzzy Mamdani”.

\section{REFERENSI}


[1] A. F. Poni Wijayanti, "Jurnal Sarjana Teknik Informatika," SISTEM PAKAR MENDIAGNOSA JENIS PENYAKIT STROKE MENGGUNAKAN METODE CERTAINTY FACTOR, vol. II, no. 1, p. 13, 2014.

[2] R. P. S. M. I. Z. Jansen Kanggeraldo, "JURNAL RESTI (Rekayasa Sistem danTeknologi Informasi)," Sistem Pakar Untuk Mendiagnosis Penyakit Stroke Hemoragik dan Iskemik Menggunakan Metode Dempster Shafer, vol. II, no. 2, p. 498, 2018.

[3] E. P. S. Ira Lina Kendayto Panjaitan, "Journal Of Informatic Pelita Nusantara," ANALISIS PERBANDINGAN METODE DEMPSTER SHAFER DENGAN METODE CERTAINTY FACTOR UNTUK MENDIAGNOSA PENYAKIT STROKE, vol. III, no. 1, p. 69, 2018.

[4] G. S. M. A. M. S. M. Romy Ramanda, PERANCANGAN APLIKASI SISTEM PAKAR UNTUK MENDIAGNOSA PENYAKIT STROKE ISKEMIK DENGAN MENGGUNAKAN BAHASA PEMOGRAMAN PHP DAN MYSQL.

[5] A. A. S. ,. E. A. M. Deby Putri Indraswari, "Journal of Environmental Engineering \& Sustainable Technology," SISTEM PENDUKUNG KEPUTUSAN DETEKSI DINI PENYAKIT STROKE MENGGUNAKAN METODE DEMPSTER-SHAFER, vol. II, no. 2, p. 97, 2015.

[6] K. H. I. W. T. Moh. Zainuddin, PENERAPAN CASE BASED REASONING (CBR) UNTUK MENDIAGNOSIS PENYAKIT STROKE MENGGUNAKAN ALGORITMA K-NEAREST NEIGHBOR, 2016.

[7] R. Dwi, "Jurnal Sistem Informasi \& Telematika (Telekomunikasi, Multimedia \& Informatika)," PEMANFAATAN CERTAINTY FACTOR DALAM MENENTUKAN JENIS PENYAKIT PENYEBAB STROKE, vol. VIII, no. 2, p. 122, 2017.

[8] T. A. S. S. Annisa Natassya, "Jurnal Sistem dan Teknologi Informasi," Case Based Reasoning Diagnosis Risiko Penyakit Stroke Menggunakan Metode Hamming Distance, vol. VII, no. 2, p. 123, 2019.

[9] G. P. Agus Ramdhani Nugraha, "JURNAL MANAJEMEN INFORMATIKA," SISTEM INFORMASI AKADEMIK SEKOLAH BERBASIS WEB DI SEKOLAH MENENGAH PERTAMA NEGERI 11 TASIKMALAYA, vol. IV, no. 2, p. 7, 2017.

[10] H. R. H. Nataniel Dengen, "Jurnal Informatika Mulawarman," Perancangan Sistem Informasi Terpadu Pemerintah Daerah Kabupaten Paser, vol. 4, no. 1, 2009. 